\title{
Study of the Health Impact of Glyphosate Misuse in Two Prefectures in Togo and Evaluation of Its Bioaccumulation in Yam
}

\author{
Essolakina P’Malinam Bafei, Kossi Metowogo, Kwashie Eklu-Gadegbeku \\ Physiopathology, Bioactive Substances and Safety Research Unit, Physiology/Pharmacology Laboratory, Faculty of Sciences, \\ University of Lomé, Lomé, Togo \\ Email: bafeijoseph@gmail.com, ekwashie@gmail.com, kossi.metowogo@gmail.com
}

How to cite this paper: Bafei, E.P., Metowogo, K. and Eklu-Gadegbeku, K. (2021) Study of the Health Impact of Glyphosate Misuse in Two Prefectures in Togo and Evaluation of Its Bioaccumulation in Yam. Occupational Diseases and Environmental Medicine, 9, 199-213.

https://doi.org/10.4236/odem.2021.94015

Received: October 22, 2021

Accepted: November 19, 2021

Published: November 22, 2021

Copyright $\odot 2021$ by author(s) and Scientific Research Publishing Inc. This work is licensed under the Creative Commons Attribution International License (CC BY 4.0).

http://creativecommons.org/licenses/by/4.0/

\begin{abstract}
In Togo, as in most sub-Saharan African countries, the use of herbicides in the field has become unavoidable. Because of ignorance, some farmers use them badly. For some health professionals, the misuse of glyphosate would be at the root of the increase of certain diseases observed in recent years. This study aims to verify whether the misuse of glyphosate has an impact on the increase of certain diseases. The study is based on surveys and analysis of soil and yam samples. Surveys are conducted among 73 glyphosate traders, 177 farmers and 34 women volunteers, victims of spontaneous abortions, congenital malformations and stillbirths, as well as on the use of hospital registers gathering data from 147 health centres in two prefectures between the years 2012 and 2018. The analysis of soil and yam samples is performed by thin-layer chromatography. The study reveals that $97.3 \%$ of traders have not received any training in pesticide management and $93.63 \%$ of farmers use glyphosate inappropriately at a higher than standard rate $(6 \mathrm{l} / \mathrm{ha})$. Epidemiological data between 2012 and 2018 revealed an increase in the number of different cases from one year to the next, with similar types of malformations to those found in the 34 women-controls. Thin layer chromatography shows that the soil and yam samples are contaminated with glyphosate. This survey reveals that the glyphosate sold in the survey area is mostly unregistered and its mismanagement would have environmental and health impacts that would justify, on the one hand, the increase in cases of spontaneous abortions, stillbirths and congenital malformations noted in the epidemiological data and, on the other hand, the contamination of soil and yam samples. However, this study requires further work on the determination of glyphosate residues in yam tubers in order to clarify whether the levels found there are detrimental.
\end{abstract}




\section{Keywords}

Glyphosate, Herbicide, Survey, Togo

\section{Introduction}

Pesticide use by farmers in developing countries has a number of serious shortcomings that are prompting researchers and health workers to correlate pesticide exposure with certain emerging diseases that were previously unknown in these countries. Poor use practices include the marketing and use of unregistered pesticides [1], improper storage, use in close proximity to homes, failure to comply with doses, unsuitability with crop types, failure to respect pre-harvest intervals, etc. These bad practices could increase the risks of environmental pollution, food contamination and population exposure, which for the most part is unaware of the effects of pesticides [2]. Several epidemiological studies have already demonstrated that glyphosate is a probable carcinogen with the occurrence in laboratory tests of hepatocellular carcinomas, leukemias and lymphomas in mice [3], as well as large skin tumors in rats [4]. Glyphosate also has proven reprotoxicity, which would lead to spontaneous abortions [5] [6] and congenital malformations such as microcephaly, anencephaly and skull malformation [7] [8]. In contrast, other studies conducted by industry present glyphosate as a low toxicity product with an oral LD50 of $2000 \mathrm{mg} / \mathrm{kg}$ in rats [9] [10]. In recent years, the Togolese population has experienced a recurrence of certain ailments such as abortion and malformations whose causes would be attributed to the misuse of glyphosate. In fact, Togo has been engaged since 2014 in an agricultural practice called "zero tillage" essentially based on the use of herbicides, especially glyphosate. However, the majority of pesticide handlers in Togo, namely traders and farmers, are illiterate and misuse them, dangerously exposing the environment and consumers to their harmful effects [11]. The objective of the present study is to verify this hypothesis through surveys of traders and farmers in two prefectures with high herbicide use rates and through chromatographic analysis of soil and yam samples.

\section{Methodology}

\subsection{Zone and Study Framework}

The study area covers the prefectures of Sotouboua and Bassar, which are respectively located about $280 \mathrm{~km}$ and $380 \mathrm{~km}$ north of Lomé. The Sotouboua prefecture is part of the central region and the Bassar prefecture belongs to the Kara region (Figure 1). Both prefectures border Ghana. The survey area has a total surface area of $6092 \mathrm{~km}^{2}$, with a population of nearly 171,014 inhabitants (RGPH, 2010) and is located between $0.7794^{\circ}$ East longitude and $9.2662^{\circ}$ North latitude. Climatically, the region enjoys a tropical Sudano-Guinean type climate, characterized by wooded savannah vegetation, trees, shrubs and grass. The two 


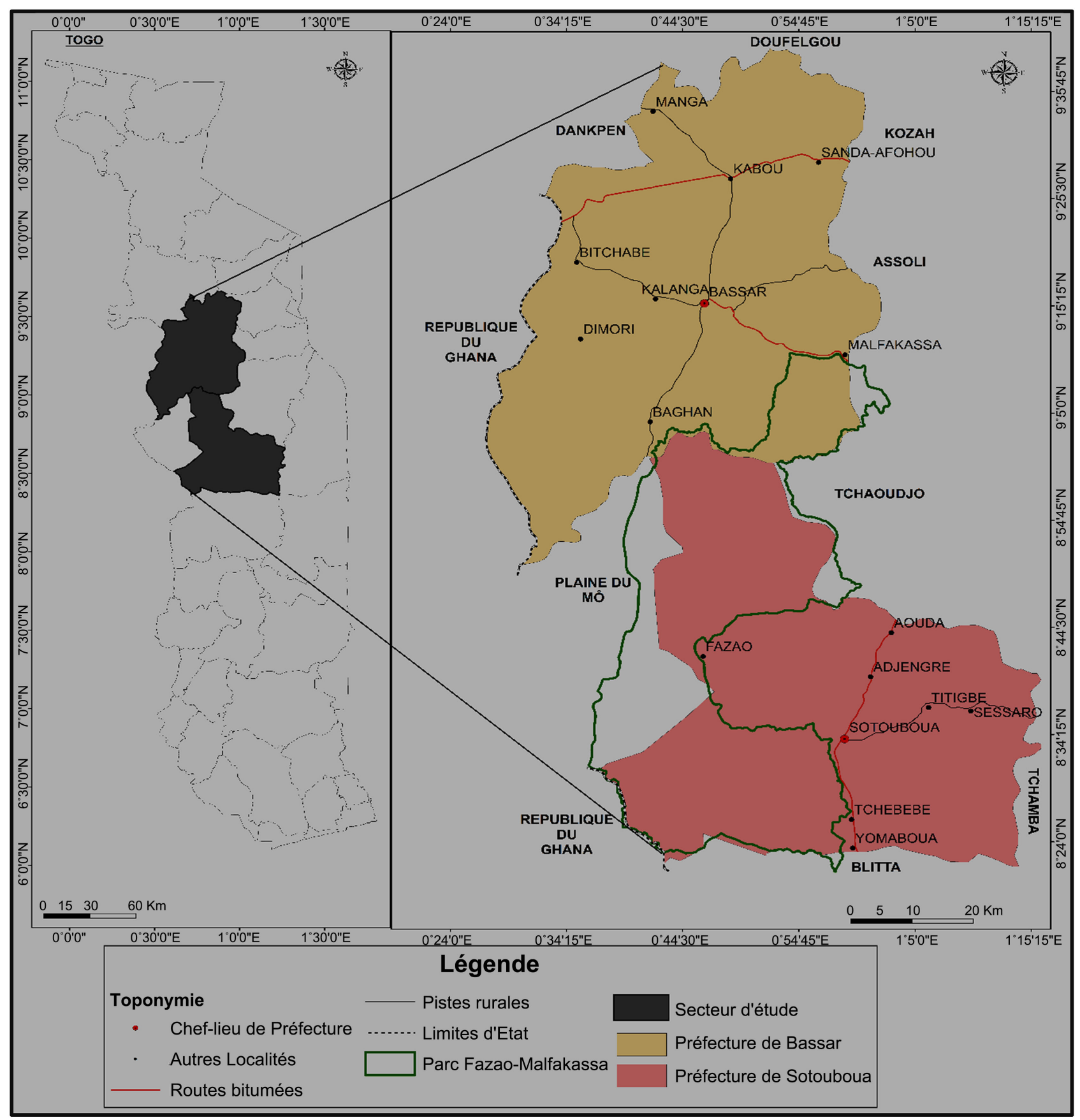

Figure 1. Map of Togo showing the prefectures of Sotouboua and Bassar.

prefectures have 21 cantons composed of nearly 450 villages. Each prefecture constitutes a health district that is responsible for several health centers whose health data are collected and compiled monthly. In total, health data were collected from 147 health facilities, both public and private.

\subsection{Method}

\subsubsection{Surveys}

The methodological approach adopted is participatory, based on individual 
semi-structured interviews, on the visit and direct observation of facilities following the method described by Orobiyi et al. [12]. The material used was mainly questionnaire sheets and hospital registers. The questionnaires were specific to each target group surveyed. The material used is mainly questionnaire sheets and hospital registers. The questionnaires are specific to each target group surveyed. Two survey campaigns are conducted. The first campaign is done from September 24 to November 08, 2018 among traders, farmers and health facilities. This survey collected data on the conditions of handling and use of glyphosate as well as epidemiological data recorded between 2012 and 2018 for cases of cancers, congenital malformations, stillbirths and spontaneous abortions. The second campaign is being conducted from April 30 to May 14, 2019, among 34 female volunteers who have experienced one or more cases of spontaneous abortion, stillbirth, and/or congenital malformations. The protocol of the different surveys was validated by the Commission for Bioethics and Research Ethics of Togo (agreement $n^{\circ} 17 /$ September 14, 2018) and the individuals were between 18 and 57 years old. The respondents' adherence was good and the data were obtained without resistance thanks to the principle of anonymity advocated by this survey.

\section{Merchant's Survey}

The survey of traders was based on a sample of 73 people working in this field, taken at random without distinction of gender. The traders were subjected to a questionnaire in order to collect the quantities of registered and unregistered glyphosate marketed annually by each trader. This made it possible to determine the percentage of registered glyphosate on the market. The survey also identified the number of traders trained in chemical management as well as the number of traders educating pesticide buyers on the importance of proper use rates and wearing personal protective equipment, as well as the dangers of using glyphosate on inappropriate crops.

\section{Farmers' Survey}

The sample size of the farmers surveyed was 177 and they were randomly selected regardless of gender. They were subjected to a questionnaire that assessed the number of farmers using glyphosate and trained in the use of pesticides, the number using personal protective equipment and the number using glyphosate on an inappropriate crop. The survey also recorded the rates of glyphosate used per hectare of yam field, the quantities of yams produced in these fields per year and the impacts observed on the harvested yam. Due to the fact that most farmers were illiterate and could not effectively quantify the rates of glyphosate used and the number of tubers produced annually, rates were estimated based on the number of vials of glyphosate used per hectare and by default, the $360 \mathrm{~g} / \mathrm{l}$ vial was considered to be used.

\section{Hospital Survey}

The epidemiological survey was based on data collection from health centres in two health districts. According to the organization of the Togolese health system, each prefecture constitutes a health district, and at the district level, all the 
health centres in the prefecture prepare and transmit their health statistics monthly to the prefectoral hospital centre, which compiles them in the form of a digitized register. Thus, the use of these digitized registers allowed us to access data from the hospital registers of 147 health centres. The information gathered is from cases of cancer, spontaneous abortions, stillbirths, and congenital malformations reported from 2012 to 2018. From these data, we calculated the percentage of spontaneous abortions to the total number of pregnant women during the year and the percentages of stillbirths and congenital malformations to the total number of births during the year.

\section{Case Control Survey}

A second epidemiological survey was conducted among 34 women volunteers whose ages ranged from 18 to 33 years and whom experienced one or more cases of spontaneous abortion, stillbirths and/or congenital malformations. The various cases were identified on the basis of information provided by community health workers and village development committees, which facilitated contact with the victims. The survey was conducted in strict anonymity, without taking the names or photographs of the respondents. Each of the 34 women was subjected to the same questionnaire, which made it possible to determine the nature and number of cases, the frequency of exposure of these women during gestation and the stage of gestation during which exposure occurred. The stage of gestation was identified on a scale of 1 to 9 months since most of the women were illiterate and therefore unable to express it by week. Similarly, the frequency of exposure was assessed by considering approximately the number of days the pregnant woman was in contact with the product regardless of location.

\subsubsection{Analysis of Soil and Yam Samples}

Glyphosate is obtained from Sinopharm Chemical Reagent Company (Shanghai, China), acetonitrile and methanol of analytical grade are purchased from Sigma Aldrich and acetic acid is obtained from Panreac Quimica SA 2-propanol and ninhydrin are purchased from Biochem chemopharma. Distilled water is used throughout the experiments.

Soil and yam samples were collected in the prefecture of Bassar, precisely in the canton of Kabou, in order to study the bioaccumulation of glyphosate. The soil samples were taken from two fields previously treated with glyphosate, one at the beginning of the season and the other for almost a year. The yam samples were collected from these two fields and from the market in Kabou to verify the impact of glyphosate use in the cultivation of this foodstuff.

Extraction of glyphosate from the soil and yam samples was performed using acetonitrile according to the method described by Adelowo et al. [13]. In a $10 \mathrm{ml}$ test tube, $5 \mathrm{~g}$ of the sample was introduced, $4 \mathrm{ml}$ of acetonitrile and $1 \mathrm{ml}$ of distilled water were added. Then the mixture is centrifuged at $1000 \mathrm{rpm}$ for $15 \mathrm{mi}-$ nutes, then the supernatant is filtered and stored at $4^{\circ} \mathrm{C}$. The determination of the presence of glyphosate in the samples was performed by thin layer chromatography according to the method described by Sprankle et al. [14]. The differ- 
ent samples were deposited on silica gel plate at $1.5 \mathrm{~cm}$ from the base of the plate. Two eluents were used namely eluent A composed of methanol-distilled water $(67: 33 \mathrm{v} / \mathrm{v})$ and eluent B composed of methanol-acetic acid-water (70:20:10 v/v). Visualization is done by spraying $0.5 \%$ ninhydrin in a 2-propanol solution and after drying the plates at $80^{\circ} \mathrm{C}$ for $5 \mathrm{~min}$ to develop the color.

\subsection{Processing of Results}

The data collected were manually tabulated and then entered and analyzed using Excel 2013 and Graph Pad Prism 6 software. This allowed calculating the percentage for each parameter. The results of the data illustrating: glyphosate management, glyphosate rates, case progression (spontaneous abortions, stillbirths, congenital malformations and cancers) between 2012 and 2018, were presented in the form of tables, histograms and curves, respectively.

\section{Results}

\subsection{Merchant's Survey}

The results obtained show that only $2.7 \%$ (2 out of 73 ) of traders have received training in pesticide management and have storage and sales warehouses with only $1.4 \%$ having the safety data sheets (SDS) for the products. The other traders do not have appropriate warehouses and most store their products at home. For the latter, products are sold exclusively in markets or on roadsides. The products are placed on tables or on tarpaulins on the ground, under the effect of heat or rain and close to foodstuffs or in combination with other items. From a quantitative point of view, it appears that nearly $84.3 \%$ of glyphosate sold in the two prefectures is not registered as shown in Figure 2. Finally, 19.17\% of traders educate pesticide buyers on the respect of doses, the wearing of personal protective equipment and the danger of using glyphosate for inappropriate crops.

\subsection{Farmers' Survey}

The results in Table 1 show that $88.70 \%$ of the farmers use glyphosate for field

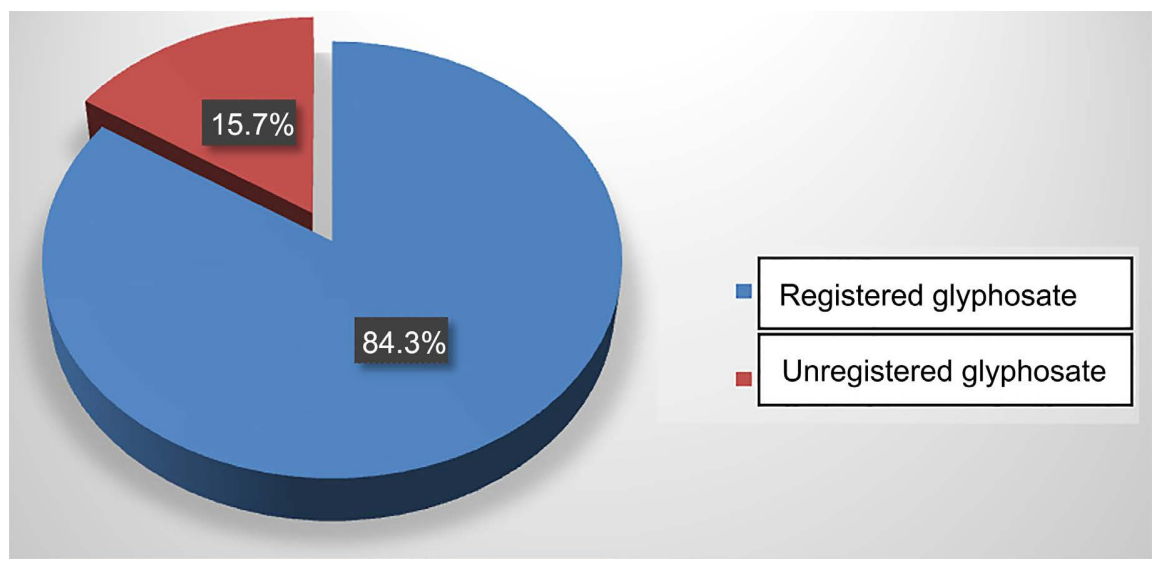

Figure 2. Rate of registered and unregistered glyphosate sold in two prefectures. 
Table 1. Data illustrating the use of glyphosate in the survey area (the number of farmers surveyed and the number of farmers cultivating yam are taken as reference values for the calculation of percentages).

\begin{tabular}{lcc}
\hline \multicolumn{1}{c}{ Title } & Total & $\begin{array}{c}\text { Percentage } \\
\text { (\%) }\end{array}$ \\
\hline Number of farmers surveyed & 177 & 100 \\
Number of growers using glyphosate & 157 & 88.70 \\
Number of farmers trained in pesticide use & 04 & 2.55 \\
Number of farmers using traditional protective equipment & 11 & 7.01 \\
Number of growers misusing glyphosate & 147 & 93.63 \\
Number of growers who have kept glyphosate at home & 119 & 75.79 \\
Number of farmers cultivating yam & 131 & 100 \\
Number of growers using glyphosate for yam cultivation & 104 & 79.38 \\
Number of growers using higher rate than normal & 99 & 95.19 \\
\hline
\end{tabular}

treatment and about $93.63 \%$ use it incorrectly either around the houses or for inappropriate crops such as yam, cassava, sweet potato and groundnut. It was also found that $97.45 \%$ of the farmers said that they had not received any training on pesticides use and nearly $75.79 \%$ had stored glyphosate at home for at least three months. In addition, no grower has adequate personal protective equipment (PPE). However, $7.01 \%$ say, they started using traditional equipment to protect themselves when they noticed skin and eye burns. They commonly use bush shoes, old long-sleeved shirts, hats or scarves, glasses and very rarely boots and gloves. With regard to yam cultivation, the survey reveals that nearly $79.38 \%$ of yam growers use glyphosate for field treatment. The rates used in the field varied from 4 to $10 \mathrm{~L} /$ ha and nearly $98.07 \%$ of glyphosate users used a higher than normal amount $(6 \mathrm{~L} / \mathrm{ha})$ and the rate most commonly used was 8 L/ha as shown in Figure 3. Finally, nearly $79.80 \%$ of users reported that yams from fields pre-treated with glyphosate rotted faster than those from untreated fields.

\subsection{Hospital Survey}

The results of the hospital survey show a sharp increase in cases of spontaneous abortions, stillbirths and congenital malformations in 2014 except for cancer, which only spiked in 2018 as shown in Figure 4. Figure 5 shows the percentages of spontaneous abortions, stillbirths, congenital malformations and cancers that also increased from year to year. The types of malformations encountered are: clubfoot, harelip, umbilical malformation, microcephaly, mental retardation, brachial plexus elongation, hydrocephaly, abdominal malformation and anencephaly. Regarding the management of poisoning cases, the survey reveals that only $16.07 \%$ of health workers have a clear knowledge of the signs of pesticide poisoning and nearly $8.92 \%$ received training to enable them to manage victims. 


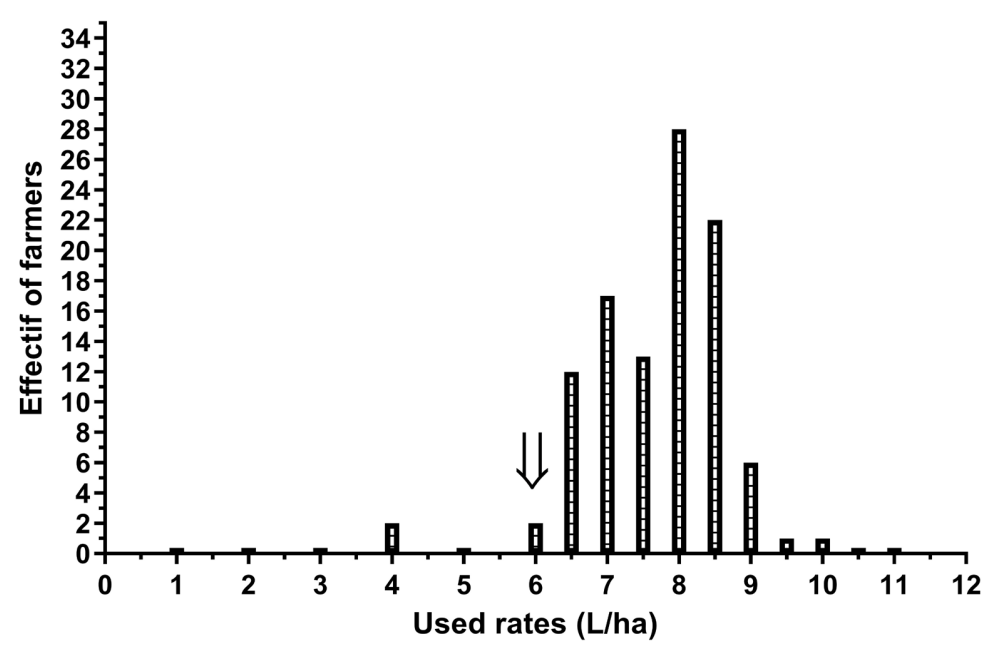

Figure 3. Glyphosate rates used in the yam field (the arrow indicates the normal rate required for corn, $6 \mathrm{~L} / \mathrm{ha}$ ).

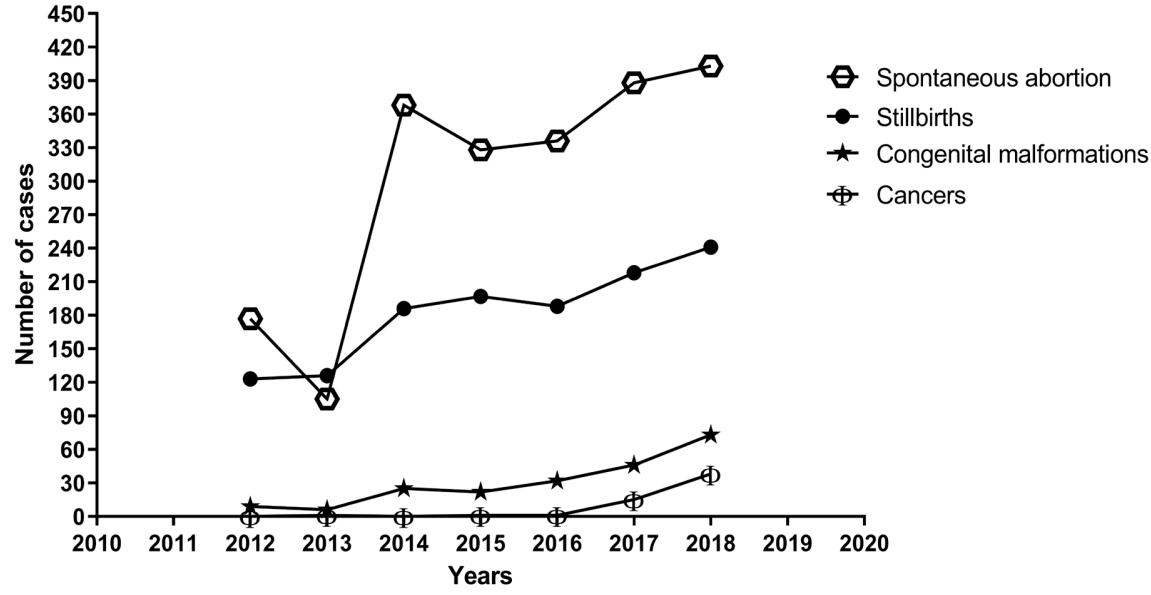

Figure 4. Curves showing the evolution of cases of spontaneous abortion, stillbirths, congenital malformations and cancers in two health districts with high glyphosate use between 2012 and 2018.

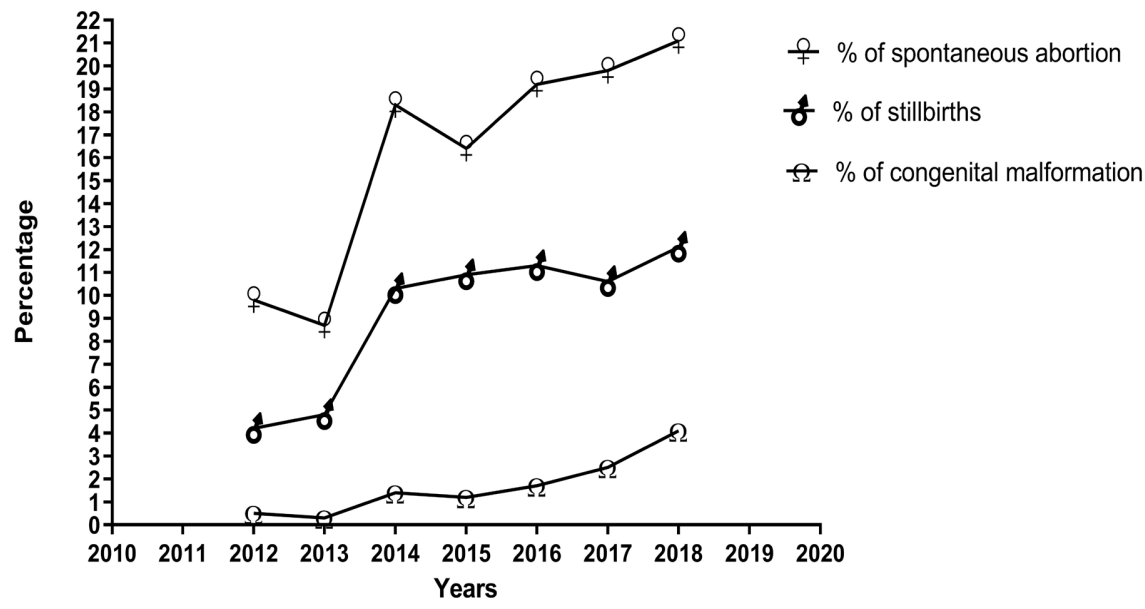

Figure 5. Curves showing the evolution of the percentages of registered cases. 


\subsection{Case Control Survey}

All of the women surveyed (control cases) reported frequent exposure to glyphosate during pregnancy without three of them. However, these women acknowledged that their husbands used this herbicide. Of the 34 women, there were 13 cases of congenital malformations, 26 cases of spontaneous abortions and 05 cases of stillbirths. Some women experienced one or two cases of the three types of ailments between the years 2015 and 2018. Regarding congenital malformations, the majority of reported cases are related to the cephalic part. They noted cases of mental retardation associated with the small head (05 cases), large head (03 cases) and open skull with visible brain (04 cases). One case of chest malformation was also raised by a 22 -year-old woman. In the majority of cases, the children did not survive beyond six months except for those with mental retardation. The stages of gestation during which women were exposed to glyphosate ranged from 1 to 6 months. Most women exposed in the field developed more spontaneous abortions, while those exposed during home storage of the product were affected by stillbirths and malformations. The latter claim that the product (or its leftovers) has been stored at home. The frequency of exposure varies between three (03) and seven (07) days during farming activities and between thirty (30) and ninety (90) days, or even until the new season in the case of home storage.

\subsection{Analysis of Soil and Yam Samples}

Analysis of the soil and yam samples by thin layer chromatography revealed the presence of glyphosate in all the soil and yam samples except for the soil taken from the field that had been treated with glyphosate for more than one year. The frontal ratio (Rf) of the different samples ranged from 0.61 to 0.62 for eluent $\mathrm{A}$ and from 0.58 to 0.60 for eluent B. The analytical results are presented in Table 2 and the chromatograms obtained are shown in Figure 6.

\section{Discussion}

The results obtained prove that most of the glyphosate sold (84.3\%) is unregistered

Table 2. Illustration of frontal ratio obtained in different eluent.

\begin{tabular}{ccc}
\hline Sample & Frontal ratio (Eluent A) & Frontal ratio (Eluent B) \\
\hline$E_{0}$ & 0.61 & 0.58 \\
$I_{t}$ & 0.61 & 0.58 \\
$I_{t}^{\prime}$ & 0.61 & 0.58 \\
$I_{m}$ & 0.62 & 0.58 \\
$I_{d}$ & 0.61 & 0.58 \\
$S$ & 0.61 & 0.57 \\
$S^{\prime}$ & - & - \\
$E_{1}$ & 0.61 & 0.57 \\
\hline
\end{tabular}




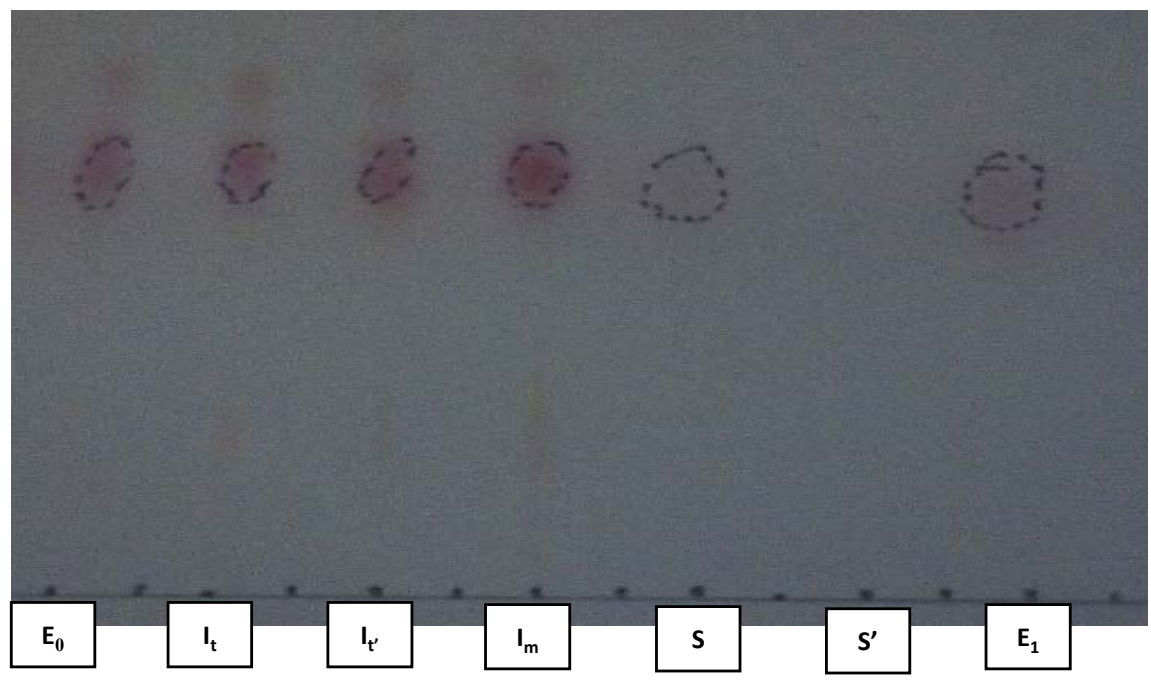

Figure 6. Chromatogram showing the presence of glyphosate in soil and yam samples through eluent B. $E_{0}$ and $E_{1}$ are the glyphosate standards; $I_{t}$ is the yam sample taken from the field treated with glyphosate in the same year; $I_{t}^{\prime}$ is the yam sample collected from the field treated with glyphosate for more than one year; $I_{m}$ is the yam sample purchased at the market; $S$ is the soil sample taken from the field treated with glyphosate the same year; $S^{\prime}$ is the soil sample taken from the field treated with glyphosate for more than one year. The percentages were calculated by relating: cases of spontaneous abortions to the total number of pregnant women during the year; cases of stillbirths and congenital malformations were added to the total number of births during the year.

and is smuggled through illicit traffic. The same finding was noted by the study of Etse et al. [2], who noted the existence of such trade in southwestern Togo, facilitated by the high porosity of the borders, especially that of Ghana [11]. All this large quantity of unregistered glyphosate has therefore not been subject to eco-toxicological evaluations by the pesticide registration committee, which should set the conditions for its use, including the doses to be applied and the types of crops. Thus, the existence of informal trade and the non-registration of pesticides, combined with the high proportion of untrained traders (97.3\%) in the sound management of pesticides, is becoming a serious threat to the environment and human health of the Togolese population. This explains the dramatic reasons why these products are sold in markets and along roadsides as well as near foodstuffs.

Such a situation is likely to increase the risks of exposure and food contamination. Furthermore, the proportion of traders (19.17\%) who claim to educate pesticide buyers seems questionable. Indeed, if only $2.7 \%$ of merchants have received training in pesticide management, we wonder what kind of education/advice the rest of the merchants could provide, especially, since the products are not registered, the labels are in English, and the majority of these merchants are illiterate and therefore unable to read labels even in French. The Toe et al. [15] study also noted that in Burkina Faso, pesticide traders do not educate buyers since they themselves receive no training in pesticide management.

With regard to the farmers, it should be noted that they misuse glyphosate, 
since $97.45 \%$ of users are not trained in the use of pesticides. This is why most of them $(93.63 \%)$ use doses higher than the dose recommended $(6 \mathrm{~L} / \mathrm{ha})$ by the Togo Pesticide Registration Committee (updated list of phytosanitary products registered in Togo, January 2017). This result is significantly higher than that of Abukari et al. [16] who found that in Ghana, only 44\% of yam farmers use glyphosate at a higher dose than recommended. He points out that the latter is completely unaware of the risk of food contamination by the product. It is probably because of this contamination that $79.80 \%$ of the users in this study found that the yams from fields pretreated with glyphosate rotted faster than those from untreated fields. Indeed, the work of Kanda et al. [17] in Togo, as well as that of Son et al. (2017) in Burkina-Faso, has shown that overdosing is largely responsible for environmental pollution and human exposure through pesticide residues. In addition, since many farmers use glyphosate for inappropriate crops, there is concern about the potential contamination of certain foodstuffs such as tubers (yam, cassava, sweet potato) and groundnuts for which the edible parts are underground. Indeed, the work of Becquera et al. [18] shows that plant roots take trace elements from the soil in the form dissolved in water and the phyto-availability of a trace element depends on the plant organ. Morel [19] showed that roots accumulate more than fruits, grains and leaves, and the work of Prasad et al. [20] adds that during their transport in the plant, trace elements are largely fixed on the cell walls, which explains why most of the elements taken up are found in the roots (about $75 \%$ to $90 \%$ ). From the above, it is assumed that yam tubers from fields pre-treated with glyphosate would be potentially contaminated with glyphosate or its metabolite, aminomethylphosphonic acid (AMPA), or even its adjuvant, polyoxyethylenamine (POEA). The latter is known to be more toxic than glyphosate according to the work of Seralini et al. [21] and confirmed by Watts and Pan [3] and Lee et al. [22].

Considering the results of thin-layer chromatography, it can be seen that the frontal ratio obtained at eluent $\mathrm{A}$ is similar to that obtained by Sprankle et al. [14]. The chromatograms reveal the presence of glyphosate in both field and market yams. Eluent B provided a better chromatogram due to the elimination of the streaks by acetic acid. However, the latter reduced the polarity of the migration solvent, which explains the decrease in frontal ratio values.

Regarding the wearing of PPE, we did not encounter any farmers using a protective mask, contrary to the result of Etse et al. [2]. This can be explained either by the fact that the farmers would have abandoned this good practice or it is the farmers in southern Togo who use it since, in this study, the prefectures surveyed are in the central and northern part of the country. The lack of protective masks proves that farmers and possibly their wives could be dangerously exposed to glyphosate during each spraying especially since they do not respect the direction of the wind and the minimum rules of hygiene and safety. Indeed, the study by Acquavella et al. [23], conducted among farmers and their families in South Carolina and Minnesota found that most of those who did not wear PPE had the highest blood levels of glyphosate. In addition, our study found that 
nearly $75.79 \%$ would have exposed their families to glyphosate vapors for at least three (03) months during home storage with a higher risk to pregnant women and fetuses.

With regard to the epidemiological data collected, it was noted that cases of spontaneous abortion and congenital malformations had tripled and quadrupled respectively from 2014 onwards. Given that this is the year that glyphosate began to be used on a large scale in Togo (zero tillage policy), it can be assumed that its misuse would have an impact on the increase in recorded cases. But this may be due to other sources of exposure or to the increase in the number of pregnant women between 2013 and 2014. However, the results in Figure 5 show that the percentages of cases are also increasing from year to year, providing sufficient evidence that the observed increase is not dependent on the increase in the number of pregnant women. On the other hand, the results of the case-control survey show many similarities with those collected at the level of the hospital survey. With regard to cancer cases, we note that there is an explosion of cases between 2017 and 2018, i.e. approximately 04 years after the start of the large-scale use of glyphosate. This is not surprising since the onset of cancer is not immediate, as in the case of spontaneous abortions, stillbirths and malformations. Although the epidemiological studies conducted by Morrison et al. [24] demonstrated, as did the work of George et al. [25], that there was a correlation between glyphosate exposure and the presence of cancers, it cannot be concluded that the increase in cancer cases observed in 2018 would be due to glyphosate since there are several other factors that can lead to cancer. A complementary study based on the analysis of cancer control cases would then be necessary.

On the other hand, with regard to cases of spontaneous abortion, stillbirths and congenital malformations, the study shows that the increase in these cases would be linked to the misuse of glyphosate, since an additional study was carried out with control cases and the results show that $91.17 \%$ ( 31 out of 34 women) of the victims recognize that they had been regular in contact with glyphosate during gestation. Even for the three women who claimed not to have been in contact with the product during pregnancy, we believe that they would have been exposed in other circumstances that they were unable to assess as a risk factor. Indeed, one of them claims to have her spare parts stall near a pesticide dealer, and all three of them acknowledge that their husbands weed their yam fields even though they believe that the product was never stored at home. It is therefore highly likely that these women would have been exposed to glyphosate or its adjuvant through the contaminated yams, whose residues would have reached a level detrimental to the survival of the fetus. Indeed, a study carried out on the blood of thirty pregnant women in Quebec revealed that $100 \%$ of these women had residues of glufosinate, a herbicide of the same family as glyphosate [26]. Most of the women who experienced birth defects and stillbirths were those who reported that the product had been stored in their homes before and after treatment. It is understandable that these women were exposed to low, repetitive doses and this exposure was not negligible. Indeed, under the effect of 
heat, the vapor pressure of the product increases and nanoparticles of the product escape from the packaging (even when closed), saturating the storage places, which turned out to be the places where the women were sedentary. Such exposure would have a lasting effect on the fetus, which would explain why these women have experienced cases of congenital malformations and stillbirths. An epidemiological study by the Ontario Farm Family Health Study also found an association between glyphosate exposure and birth defects and spontaneous abortions [5] [6]. Similarly, Watts and Pan [7] and Carrasco and al. [8] reported cases of congenital malformations such as microcephaly, anencephaly and skull malformation in women chronically exposed to glyphosate during pregnancy. Mose et al. [27] have shown that glyphosate readily crosses the placenta, with a $15 \%$ transfer from maternal to fetal circulation. And it is these types of malformations that have been noted in both the control cases and the hospital data treated in this study. On the other hand, the women who most often had spontaneous abortions were exposed during the field treatments. It is therefore understandable that massive exposure to high doses would cause spontaneous abortion in pregnant women. In such cases, glyphosate or its adjuvant may cause contractile effects on the uterine muscle at a given dose. Finally, all these control cases were recorded over the period from 2015 to 2018, which is consistent with the period of large-scale use of glyphosate in Togo. It could be concluded that the misuse of glyphosate would have an impact on the increase of spontaneous abortions, stillbirths and congenital malformations.

\section{Conclusion}

In view of all the bad practices of handling and use of glyphosate in the prefectures of Bassar and Sotouboua, it appears that most the traders, farmers and residents of the cultivated areas would be highly exposed to glyphosate. This exposure would occur during storage, handling and spraying of the product in the fields which are sometimes located around homes in rural areas. Contamination could also occur through contaminated food as revealed by TLC chromatography. The results of this study, therefore, show that glyphosate would have an impact on the increase in cases of spontaneous abortions, stillbirths and congenital malformations observed between 2014 and 2018. On the other hand, the impact on the increase in cancer cases remains to be proven and this requires an additional study based on the analysis of cancer control cases. In addition, it would be important in perspective, to proceed to the dosage of the residues of glyphosate or POEA in yam or even in the blood of certain patients.

\section{Conflicts of Interest}

The authors declare that they have no actual or potential competing financial interests.

\section{References}

[1] Ahouangninou, C., Fayomi, B.E. and Martin, T. (2011) Évaluation des risques sanitaires 
et environnementaux des pratiques phytosanitaires des producteurs maraîchers dans la commune de Tori-Bossito (Sud-Bénin). Cahiers Agricultures, 20, 216-222. https://doi.org/10.1684/agr.2011.0485

[2] Etse, K., Kanda, M., Akpavi, S., Wala, K., Batawila, K. and Akpagana, K. (2014) Apparition d'un commerce informel de produits phytosanitaires dans le sudouest du Togo. European Scientific Journal, 10, 271-283.

[3] Watts, M. and Pan, A.P. (2009) Mononograph on Glyphosate. Pesticide Action Network Asia \& the Pacific, Penang.

[4] Seralini, G.E., Clair, E., Mesnage, R., Gress, S., Defarge, N., Malatesta, M., Hennequin, D. and De Vendomois, J.S. (2012) Long Term Toxicity of a Roundup Herbicide and a Roundup-Tolerant Genetically Modified Maize. Food and Chemical Toxicology, 50, 4221-4231. https://doi.org/10.1016/j.fct.2012.08.005

[5] Savitz, D.A., Arbuckle, T., Kaczor, D. and Curtis, K.M. (1997) Male Pesticide Exposure and Pregnancy Outcome. American Journal of Epidemiology, 146, 1025-1036. https://doi.org/10.1093/oxfordjournals.aje.a009231

[6] Arbuckle, T.E., Lin, Z. and Mery, L.S. (2001) An Exploratory Analysis of the Effect of Pesticide Exposure on the Risk of Spontaneous Abortion in an Ontario Farm Population. Environmental Health Perspectives, 109, 851-857. https://doi.org/10.1289/ehp.01109851

[7] Watts, M. and Pan, A.P. (2012) Mononograph on Glyphosate: Addendum 2012. Pesticide Action Network Asia \& the Pacific, Penang.

[8] Carrasco, A.E., Paganelli, A., Gnazzo, V., Acosta, H. and Lopez, S.L. (2010) Glyphosate-Based Herbicides Produce Teratogenic Effects on Vertebrates by Impairing Retinoic Acid Signaling. Chemical Research in Toxicology, 23, 1586-1595.

https://doi.org/10.1021/tx1001749

[9] Williams, G.M., Kroes, R. and Munro, I.C. (2000) Safety Evaluation and Risk Assessment of the Herbicide Roundup and Its Active Ingredient, Glyphosate, for $\mathrm{Hu}$ mans. Regulatory Toxicology and Pharmacology, 31, 117-165. https://doi.org/10.1006/rtph.1999.1371

[10] European Food Safety Authority (2015) Conclusion on the Peer Review of the Pesticide Risk Assessment of the Active Substance Glyphosate. EFSA Journal, 13, 4302-4409. https://doi.org/10.2903/j.efsa.2015.4302

[11] Aliaki, E. (2018) Contribution aux bonnes pratiques de maraîchage: Culture in Situ et in Vitro d'Aeollanthus pubescens benth et d'ocimum canum sims en vue de leur utilisation comme biopesticides végétales. Thèse en Faculté des sciences, Université de Lomé, Lomé.

[12] Orobiyi, A., Dansi, A., Assogba, P., Loko, L.Y., Dansi, M., Vodouhè, R. and Sanni, A. (2013) Chili (Capsicum annuum L.) in Southern Benin: Production Constraints, Varietal Diversity, Preference Criteria and Participatory Evaluation. International Research Journal of Agricultural Science and Soil Science, 3, 107-120.

[13] Adelowo, F.E., Olu-Arotiowa, O.A. and Amuda, O.S. (2014) Biodegradation of Glyphosate by Fungi Species. Advances in Bioscience and Bioengineering, 2, 104-118.

[14] Sprankle, P., Sandberg, C.L., Meggitt, W.F. and Penner, D. (1978) Separation of Glyphosate and Possible Metabolites by Thin-Layer Chromatography. Weed Science, 26, 673-674. https://doi.org/10.1017/S0043174500064808

[15] Toe, A.M., Ouedraogo, M., Ouedraogo, R., Ilboudo, S. and Guissou, P.I. (2013) Pilot Study on Agricultural Pesticide Poisoning in Burkina Faso. Interdisciplinary Toxicology, 6, 185-191. https://doi.org/10.2478/intox-2013-0027 
[16] Abukari, W. (2015) The Pesticides Law and the Attitudes of Pesticides Dealers in the Northern Region of Ghana: Implications for Environmental Security and $\mathrm{Hu}$ man Health. Journal of Environment and Earth Science, 5, 227-233.

[17] Kanda, M., Akpavi, S., Wala, K., Djaneye-Boundjou, G. and Akpagana, K. (2014) Diversité des espèces cultivées et contraintes à la production en agriculture maraîchère au Togo. International Journal of Biological and Chemical Sciences, $\mathbf{8}$, 115-127. https://doi.org/10.4314/ijbcs.v8i1.11

[18] Becquera, T., Quantinb, C., Sicotc, M. and Boudotb, J.P. (2003) Chromium Availability in Ultramafic Soils from New Caledonia. Science of the Total Environment, 301, 251-261. https://doi.org/10.1016/S0048-9697(02)00298-X

[19] Morel, J.L. (1997) Bioavailability of Trace Elements to Terrestrial Plants. Soil Ecotoxicology, 6, 142-167.

[20] Prasad, M.N.V., Malec, P., Waloszek, A., Bojko, M. and Strzałka, K. (2001) Physiological Responses of Lemna trisulca L. (Duckweed) to Cadmium and Copper Bioaccumulation. Plant Science, 161, 881-889.

https://doi.org/10.1016/S0168-9452(01)00478-2

[21] Lee, H.L., Kan, C.D., Tsai, C.L., Liou, M.J. and Guo, H.R. (2009) Comparative Effects of the Formulation of Glyphosate-Surfactant Herbicides on Hemodynamics in Swine. Clinical Toxicology, 47, 651-658.

https://doi.org/10.1080/15563650903158862

[22] Richard, S., Seralini, G.E., Moslemi, S., Sipahutar, H. and Benachour, N. (2005) Differential Effects of Glyphosate and Roundup on Human Placental Cells and Aromatase. Environmental Health Perspectives, 113, 716-720.

https://doi.org/10.1289/ehp.7728

[23] Acquavella, J.F., Bruce, H.A., Mandel, J.S., Gustin, C., Baker, B., Chapman, P. and Bleeke, M. (2004) Glyphosate Biomonitoring for Farmers and Their Families: Results from the Farm Family Exposure Study. Environmental Health Perspectives, 112, 321-326. https://doi.org/10.1289/ehp.6667

[24] Morrison, H.I., Wilkins, K., Semenciw, R., Mao, Y. and Wigle, D. (1992) Herbicides and Cancer. Journal of the National Cancer Institute, 84, 1866-1874.

https://doi.org/10.1093/jnci/84.24.1866

[25] George, J., Prasad, S., Mahmood, Z. and Shukla, Y. (2010) Studies on GlyphosateInduced Carcinogenicity in Mouse Skin: A Proteomic Approach. Journal of Proteomics, 73, 951-964. https://doi.org/10.1016/j.jprot.2009.12.008

[26] Aris, A. and Leblanc, S. (2011) Maternal and Fetal Exposure to Pesticides Associated to Genetically Modified Foods in Eastern Townships of Quebec, Canada. Reproductive Toxicology, 31, 528-533. https://doi.org/10.1016/j.reprotox.2011.02.004

[27] Mose, T., Kjaerstad, M.B., Mathiesen, L., Nielsen, J.B., Edelfors, S. and Knudsen, L.E. (2008) Placental Passage of Benzoic Acid, Caffeine, and Glyphosate in an Ex Vivo Human Perfusion System. Journal of Toxicology and Environmental Health, Part A, 71, 984-991. https://doi.org/10.1080/01932690801934513 